\title{
When It Pays to Catch a Swarm-Evaluation of the Economic Importance of Remote Honey Bee (Apis mellifera) Colony Swarming Detection
}

\author{
Aleksejs Zacepins ${ }^{1}$, Armands Kviesis ${ }^{1}$, Vitalijs Komasilovs ${ }^{1}$ and Robert Brodschneider ${ }^{2, *(D)}$ \\ 1 Department of Computer Systems, Faculty of Information Technologies, Latvia University of Life Sciences \\ and Technologies, Liela iela 2, LV-3001 Jelgava, Latvia; aleksejs.zacepins@llu.lv (A.Z.); \\ armands.kviesis@llu.lv (A.K.); vitalijs.komasilovs@llu.lv (V.K.) \\ 2 Institute of Biology, University of Graz, Universitätsplatz 2, $8010 \mathrm{Graz}$, Austria \\ * Correspondence: robert.brodschneider@uni-graz.at
}

check for updates

Citation: Zacepins, A.; Kviesis, A.; Komasilovs, V.; Brodschneider, R.

When It Pays to Catch a

Swarm-Evaluation of the Economic Importance of Remote Honey Bee (Apis mellifera) Colony Swarming Detection. Agriculture 2021, 11, 967. https://doi.org/10.3390/ agriculture11100967

Academic Editor: Randolf Menzel

Received: 19 August 2021

Accepted: 3 October 2021

Published: 4 October 2021

Publisher's Note: MDPI stays neutral with regard to jurisdictional claims in published maps and institutional affiliations.

Copyright: (c) 2021 by the authors. Licensee MDPI, Basel, Switzerland. This article is an open access article distributed under the terms and conditions of the Creative Commons Attribution (CC BY) license (https:/ / creativecommons.org/licenses/by/ $4.0 /)$.

\begin{abstract}
Precision beekeeping, or precision apiculture, focuses on individual beehive remote monitoring using different measurement systems and sensors. Sometimes, there are debates about the necessity for such systems and the real-life benefits of the substitution of bee colony manual inspection by automatic systems. Remote systems offer many advantages, but also have their disadvantages and costs. We evaluated the economic benefits of the remote detection of the bee colonies' reproductive state of swarming. We propose two economic models for predicting differences in the benefits of catching a swarm depending on its travel distance. Models are tested by comparing the situation in four different countries (Austria, Ethiopia, Indonesia, and Latvia). The economic model is based on financial losses caused by bee colony swarming and considers the effort needed to catch the swarm following a remote swarm detection event. The economic benefit of catching a swarm after a remote precision beekeeping notification is shown to be a function of the distance/time to reach the apiary. The possible technical range is tempting, but we demonstrated that remote sensing is economically limited by the ability to physically reach the apiary and interact in time, or alternatively, inform a person living close by. An advanced economic model additionally includes the swarm catching probability, which decreases based on travel distance/time. Based on exemplary values from the four countries, the economic potential of detecting and informing beekeepers about swarming events is calculated.
\end{abstract}

Keywords: precision apiculture; bee colony swarming; remote swarming detection; economics of swarming detection

\section{Introduction}

Honey bees (Apis mellifera L.) are economically the most important managed insects [1,2]). First, honey bees are important pollinators, [3-5] and, secondly, they provide income through hive products (honey, pollen, propolis, wax, royal jelly). The global honey consumption is increasing, and honey imports, for example, to the US or EU markets are constantly growing [6]. On the other hand, colony numbers have been decreasing in these regions during the last years, partly due to political or socioeconomic reasons [7-9]. A significant decrease in honey bee colonies can affect the whole agricultural production chain, but during recent years, increases in the number of colonies and the number of beekeepers have been registered in some European countries $[9,10]$. The population of managed colonies fluctuates over time, and recent monitoring reports show different levels of colony losses in many regions and countries [11,12]. The economic impact of colony losses was recently calculated for three countries [13].

To improve the understanding of honey bee colony processes, including colony collapse, many automation and sensing technologies have been introduced to conduct research 
and carry out beekeeping. The technological inventions and their implementation for honey bee colony monitoring are summarised under the term 'precision beekeeping' or 'precision apiculture'. Precision beekeeping is defined as an apiary management strategy based on the remote monitoring of individual honey bee colonies to minimise resource consumption and maximise the productivity of bees [14]. This enables inspections, treatments or management actions in individual hives only, thus minimising the time needed for inspections and minimising the disturbance of bee colonies.

Researchers and practitioners mention several useful parameters of the bee colony for remote automated monitoring [15]. Inside the hive, temperature and humidity are the most used metrics in the realisation of precision beekeeping [14,16-18]. Hive weight is a useful metric for monitoring the productivity of a colony [19-21]. In addition, monitoring acoustics can be used for the prediction of swarming behaviour [22,23]. This list can be extended with additional monitoring parameters, like vibration, measuring various gases, etc., but its value for the beekeeper and economic feasibility is still under discussion.

With the rapid development and implementation of various information technologies in almost all aspects of human life, it is hard to imagine any of the agricultural branches not using them. There are many positive aspects of honey bee colony remote monitoring, mainly decreasing the production costs due to travel and inspection and, hence, labour hours. The remote monitoring of bee colonies can save up to $25 \%$ of costs by reducing the number of inspections. Additionally, bees are disturbed less often during the year if beekeepers use remote sensing technologies and can focus on hives that really need inspection [14]. Beekeepers can receive different alarms or targeted notifications from remote monitoring systems about the status of the monitored colonies. Ideally, this is accompanied by a decision support system [15].

Notification of a swarming event of a colony should be a basic function of remote monitoring. Swarming is a natural way of reproduction of the bee colony, when the queen bee leaves the hive with a group of worker bees to establish a new colony [24-27]. The first (prime) swarm is headed by the colony's own queen and leaves the nest a few days before the new queens emerge. The prime swarm first gathers near the old colony. Scout bees search for a new nest site, where the swarm settles and establishes a new colony. In cases where the original colony is still strong, a newly emerged queen can leave the hive with an afterswarm (cast). The main disadvantage of swarming for beekeeping for profit is that the swarmed colonies have very low productivity $[28,29]$. Swarming events can be remotely detected by temperature measurements [17,30,31], sound analysis [22], vibration frequencies [23], weight monitoring [32,33], bee counters [34], or video monitoring of the hive entrance [35]. Examples of swarming identification based on temperature and weight are shown in 1. It is necessary to emphasise that the detection of a swarming event is highly dependent on the temperature measurement interval and the position of the sensor [17]. The spike in temperature only lasts for about 20-30 min, therefore, less frequent temperature measurements cannot detect swarming. In relation to the weight change during swarming, colonies can suddenly lose several $\mathrm{kg}$. In the example in Figure $1 \mathrm{~b}$, the weight dropped by $2.6 \mathrm{~kg}$, which concurs with swarm weights identified by Villa [36].

Beekeepers apply different bee colony management techniques to reduce swarming events. However, it is impossible to fully exclude swarming in apiculture, especially with many colonies kept on a multitude of apiaries. This is where technology can help to deal with this event if it happens, or even before it occurs. The idea behind this research is that if a colony has swarmed, beekeepers still have some time (from a few hours to more than a day [37]) to catch the swarm and place it back into the hive or a new box. By catching the swarm, beekeepers can minimise the financial losses caused by unwanted bee colony swarming. For instance, beekeepers in some regions place empty boxes at remote apiaries as a trap for swarmed colonies or feral colonies. This practice does not reliably compensate economic losses resulting from swarming. The aim of this paper is to calculate the economic aspects of the benefit of catching a (remote) bee swarm after a precision beekeeping (or any other) notification. We do not consider the development, implementation and maintenance 
costs of monitoring systems and/or the return on investment coefficients, as in the case in another paper [38]. Rather, we compare the real 2019 values of bees, bee products and labour and travel costs related to catching a remote honey bee swarm after swarming detection to investigate when it is financially beneficial to try to catch the swarm. As we hypothesise that this is a function depending on distance that needs to be covered, as well as the costs for travel, labour and the value of bees and bee products, we exemplarily compare our model calculations for two European countries, one Asian country and one African country. The comparative approach also helps to illustrate the differences in precision beekeeping based on the price of bee products and the cost of living in four different countries.
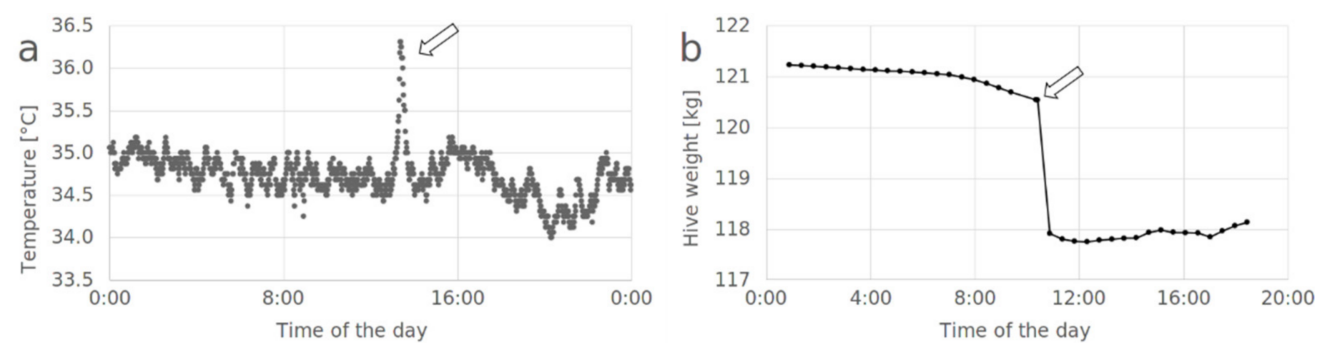

Figure 1. Examples for swarm detection based on in-hive temperature (a) and hive weight (b). Temperature was monitored every minute above the brood nest in a colony located in Jelgava, Latvia on 31 May 2018 with a temperature sensor (Dallas DS18S20, Maxim Integrated, San Jose, CA, USA). The weight of a hive located in Vecauce, Latvia was monitored every $30 \mathrm{~min}$ on 11 June 2021. Arrows indicate the departure of the swarms.

\section{Materials and Methods}

An evaluation of the economic importance of remote bee colony swarming detection is performed by proposing several equations for the calculation of financial losses caused by bee colony swarming and evaluating the expenses that emerge as a result of travelling to remote apiaries and catching the swarm. We developed two economic models for the evaluation of catching a swarm. The first model is an economic model including travelled distance (see Section 3.1) and the second is the advanced economic model including swarm catch probability (see Section 3.2).

Sample calculations are made for Austria, Ethiopia, Indonesia, and Latvia. To ease the process of calculations, a web tool was developed and published online for public use.

\subsection{Calculation of Financial Losses Caused by Honey Bee Colony Swarming}

Honey bee colony swarming results in the loss of a mated queen bee and a significant amount of worker bees that leave the hive. The exact number of bees leaving the hive is difficult to determine, but there are estimations that the fraction of a fissioning colony's workforce that leaves with the swarm ranges from 0.4 to 0.8 [27,39]. Seeley and Rangel [40] found that on average $75 \%$ of a colony's worker population left the parental nest with the (old) mother queen, while only $25 \%$ stayed behind with the (young) daughter queen. Based on this, it can be concluded that if the swarm is not caught, beekeepers lose one queen bee and $75 \%$ of the worker bees. The mother colony becomes weaker, experiences a gap in the emergence of adult honey bees and is not able to collect nectar with the previous strength and speed. Thus, beekeepers will also lose income from the honey that could potentially have been collected by a non-swarming colony. The new queen will start to produce eggs (and thus new bees), but it needs another 21 days until the first young bees eclose. A precise estimation of the potential loss of uncollected honey is even more difficult. Many factors can affect this amount, for example, the time at which swarming occurred. If swarming occurred before the main nectar flow, the colony would potentially have time to restore the worker population, and economic losses will be lower. On the other hand, if a colony swarms during nectar flow, honey collection is reduced further. As there is no 
published data available on the loss of honey through swarming, we assume this to be about half of the potential honey harvest.

A calculation of the potential losses caused by honey bee colony swarming should consist of two parts: the first related to the bees, and the second related to the potentially uncollected honey. We propose the following formula for the potential economic loss calculation for honey bee colony swarming:

$$
\text { Potential losses }\left(\mathrm{L}_{\text {pot }}\right)=\mathrm{P}_{\text {queen }}+\left(\mathrm{P}_{\text {bee }}{ }^{*} \text { NumOfBees }\right)+\left(\mathrm{L}_{\text {honey }}{ }^{*} \mathrm{P}_{\text {honey }}\right),
$$

where:

$\mathrm{P}_{\text {queen }}=$ Price of the bee queen $(\mathrm{EUR})$

$\mathrm{P}_{\text {bee }}=$ Price of one bee (EUR)

NumOfBees $=$ Number of bees leaving the hive (all worker bees in the colony * 0.75 (small colony up to 7000 worker bees, large colony-up to 30,000 worker bees)

$\mathrm{L}_{\text {honey }}=$ Potentially uncollected honey $(\mathrm{kg})$ (half of the average honey production per colony per season)

$\mathrm{P}_{\text {honey }}=$ Honey price per $\mathrm{kg}(\mathrm{EUR})$

The bee-related part of the formula can alternatively be substituted by the average price of the caught swarm in the target country if such information is available. If wished, yields of other bee products such as wax, pollen or propolis, which in some areas are a significant source of income, can also be added to the equation, but we only concentrate on honey production in this article.

\subsection{Calculation of Expenses to Reach the Apiary and Catch the Swarm}

In our approach, we model the situation in which a beekeeper has an apiary located at a remote place and requires going there by car (or by a different means of transport) to catch the swarm. Like the previous formula $\left(\mathrm{L}_{\mathrm{pot}}\right)$, these expenses also consist of two parts: one is related to travel costs, including car fuel consumption, and the other is related to labour costs. To calculate the expenses related to fuel consumption, the distance to the apiary is needed, along with the car fuel consumption per $100 \mathrm{~km}$ and fuel price. As an alternative, the constant cost for kilometre allowance can be used for calculations (in this case maintenance expenses of the car are also derived from its use). For labour-related expenses, time for swarm catching, time for travelling to the apiary and the person's (or persons') salary are taken into account. We would like to emphasise that even if the distance is $0 \mathrm{~km}$, it does not mean that the working time is $0 \mathrm{~h}$, since time is needed to capture the swarm. We propose the following formula for calculating the expenses to reach the apiary and catch the swarm:

$$
(\operatorname{Exp})=\operatorname{Exp}_{\text {fuel }}+\text { Exppers }
$$

where:

$$
\operatorname{Exp}_{\text {fuel }}=\text { Dist }^{*} \text { Fuel }_{\text {cons }} / 100 * \text { Fuel }_{\text {price }}(\text { EUR }),
$$

Dist $=$ Distance to the apiary $(\mathrm{km})$

Fuel $_{\text {cons }}=$ Car fuel consumption for $100 \mathrm{~km}(\mathrm{~L})$

Fuel $_{\text {price }}=$ Price of one litre of fuel (EUR)

$$
\operatorname{Exp}_{\text {pers }}=\text { Num }_{\text {pers }} *\left(\text { Pers }_{\text {time }} * \text { Pers }_{\text {hour }}\right),
$$

where:

Numpers $_{\text {p }}$ Number of persons involved in catching the swarm

Pers time $=$ Time needed to catch the swarm, including travelling time (hours). This variable can also include additional time, for example traffic, time for swarm detection, ability to start off immediately etc.

Pers $_{\text {hour }}=$ Salary for one person per hour (EUR) 


\subsection{Estimation of Parameters for Austria, Ethiopia, Indonesia and Latvia}

Different data sources were used in the four studied countries, in order to set parameters for calculations. In Austria, expert opinions were collected, as well as official information published by the Federal Ministry of Sustainability and Tourism [41]. For Ethiopia, data based on a report from the Ethiopian Centre and regional Offices of Livestock were used. In Indonesia, the data were collected in a survey of beekeepers in six regions around West Java (Sukabumi, Subang, Cianjur, Bandung, Majalengka and Ciwidey). Six Apis cerana beekeepers (stationary beekeeping) and two (migratory) A. mellifera beekeepers responded to a questionnaire. In Indonesia, the wage was calculated per day because it is difficult to find labour that ask for a wage per hour. This means that the salary for two working hours and for eight working hours is the same. In Latvia, consultations with expert beekeepers and beekeepers' homepage analysis were conducted to identify the exact numbers for variables. For Latvia, the price of a honey bee queen is estimated to be EUR 15 (based on http://indrani.lv/produkcija/, accessed on 25 August 2021). The average honey production in Latvia is $25 \mathrm{~kg}$ per colony, so the potential loss could be $12.5 \mathrm{~kg}$ (based on http:/ / www.strops.lv/index.php/raksti/dravosanas-panemieni/467lbb-biskopju-aptaujas-rezultatu-apkopojums, accessed on 25 August 2021). The price of honey in Latvia is on average $4.5 \mathrm{EUR} / \mathrm{kg}$ (based on http://laukos.la.lv/biskopji-spejtik-medu-sviest, accessed on 25 August 2021). The wage in Latvia is based on data from the State Revenue Service (https:/ / www.vid.gov.lv/lv/statistika / profesiju-atalgojums, accessed on 25 August 2021).

\section{Results}

The financial value of a honey bee swarm in the four given countries is shown in Table 1. The calculation is made based on the equation given in Section 2.1 ( $\left.\mathrm{L}_{\mathrm{pot}}\right)$. The potential economic losses are highest in Austria, because of the highest honey price (row $\mathrm{L}_{\text {pot }}$ in Table 1). Table 1 additionally shows exemplary calculations of the economic model including ravelled distance for the four countries. For comparison, variables for the number of bees in the swarm, the distance to the apiary, fuel consumption, the number of persons and the time spent are considered equal for each country.

An exemplary calculation of potential economic losses caused by colony swarming and expenses related to travelling to the remote apiary for the Latvian market situation is as follows:

$\mathrm{L}_{\text {pot }}=50+12.5 * 4.5=$ EUR 106.25

$\operatorname{Exp}_{\text {fuel }}=100 * 8 / 100 * 1.20=$ EUR 9.6

$\operatorname{Exp}=9.6+21.44=$ EUR 31.04

When all expenses are calculated, beekeepers can evaluate the overall economic benefit of catching the swarm by subtracting Exp from $\mathrm{L}_{\text {pot }}$.

$$
\mathrm{Bnf}=\mathrm{L}_{\text {pot }}-\mathrm{Exp},
$$

In the example for Latvia, it should be as follows:

Bnf $=106.25-31.04=$ EUR 75.21

In this case, a beekeeper would save EUR 75.21, which is $71 \%$ of the swarm's value if they get notified by a remote swarming monitoring system and it is possible to travel to the apiary and catch the swarm. In this example, the travel distance is $100 \mathrm{~km}$; beekeepers in the four countries save between 69 and $86 \%$ of the potential losses of a swarm, if they can catch the swarm $\left(\mathrm{Bnf} / \mathrm{L}_{\text {pot }}(\%)\right.$, Table 1$)$. 
Table 1. Example calculation for the economic model including travelled distance for four countries.

\begin{tabular}{|c|c|c|c|c|}
\hline Variable/Country & Austria & Ethiopia & Indonesia & Latvia \\
\hline Number of bees, NumOfBees & \multicolumn{4}{|c|}{$15000 * 0.75=11250$} \\
\hline $\begin{array}{l}\text { Total distance to and back from the } \\
\text { remote apiary, Dist }(\mathrm{km})\end{array}$ & \multicolumn{4}{|c|}{100} \\
\hline Fuel consumption, Fuel cons (L) & \multicolumn{4}{|c|}{8} \\
\hline $\begin{array}{l}\text { Time needed to catch the swarm, } \\
\text { including travelling time, Pers time }(\mathrm{h})\end{array}$ & \multicolumn{4}{|c|}{4} \\
\hline $\begin{array}{l}\text { Number of persons going to the } \\
\text { remote apiary, Num pers }\end{array}$ & \multicolumn{4}{|c|}{1} \\
\hline Price of the bee queen, $P_{\text {queen }}(E U R)$ & 27.5 & - & - & 15 \\
\hline Price of one bee, $\mathrm{P}_{\text {bee }}$ (EUR) & 0.006 & - & - & 0.006 \\
\hline Price of the bee swarm, $P_{\text {swarm }}$ (EUR) & 70.00 & 12.00 & 50.00 & 50.00 \\
\hline $\begin{array}{l}\text { Potentially uncollected honey, L honey } \\
\text { (kg/colony) }\end{array}$ & 10.0 & 17.5 & 10.0 & 12.5 \\
\hline Honey price, $P_{\text {honey }}(\mathrm{EUR} / \mathrm{kg})$ & 12.50 & 2.73 & 4.67 & 4.50 \\
\hline Potential loses, $\mathrm{L}_{\text {pot }}$ (EUR) & 195.00 & 59.78 & 96.70 & 106.25 \\
\hline $\begin{array}{l}\text { Salary for one person hour, Pers hour } \\
\text { (EUR) }\end{array}$ & 12.50 & 1.08 & 7.79 & 5.36 \\
\hline Price of fuel, Fuel price (EUR per Litre) & 1.20 & 0.58 & 0.74 & 1.20 \\
\hline $\begin{array}{l}\text { Expenses related to travelling to the } \\
\text { remote apiary, Exp (EUR) }\end{array}$ & 59.60 & 8.96 & 13.71 & 31.04 \\
\hline $\begin{array}{l}\text { Overall economic benefit of catching } \\
\text { the swarm, Bnf (EUR) }\end{array}$ & 135.40 & 50.82 & 82.99 & 75.21 \\
\hline $\begin{array}{c}\text { Savings of the potential losses of a } \\
\text { swarm, Bnf } / L_{\text {pot }}(\%)\end{array}$ & $69 \%$ & $85 \%$ & $86 \%$ & $71 \%$ \\
\hline
\end{tabular}

\subsection{Economic Model including Travelled Distance}

Figure 2 shows the economic model including travelled distance for predicting benefits for catching a swarm in four different countries depending on travel distances. The model suggests different slopes and intercepts for the four countries, whereby the slope is defined by travel and labour costs, and the intercepts reflect the value of bees and their products (Figure 2). It is worth noting that, on short distances, the majority of the benefit is defined by the cost of potentially saved colony and/or caught swarm. Meanwhile, for distant apiaries, a significant part of the potential benefit is consumed by travel and personnel costs. The distances that can be travelled until no more financial benefits of catching a swarm differ from country to country. It is highest in Indonesia (equal to $1502 \mathrm{~km}$ ), whereas it is $500 \mathrm{~km}$ both ways in Austria. These numbers are calculated based on the formula from Figure 2, where the benefit is equal to zero. 


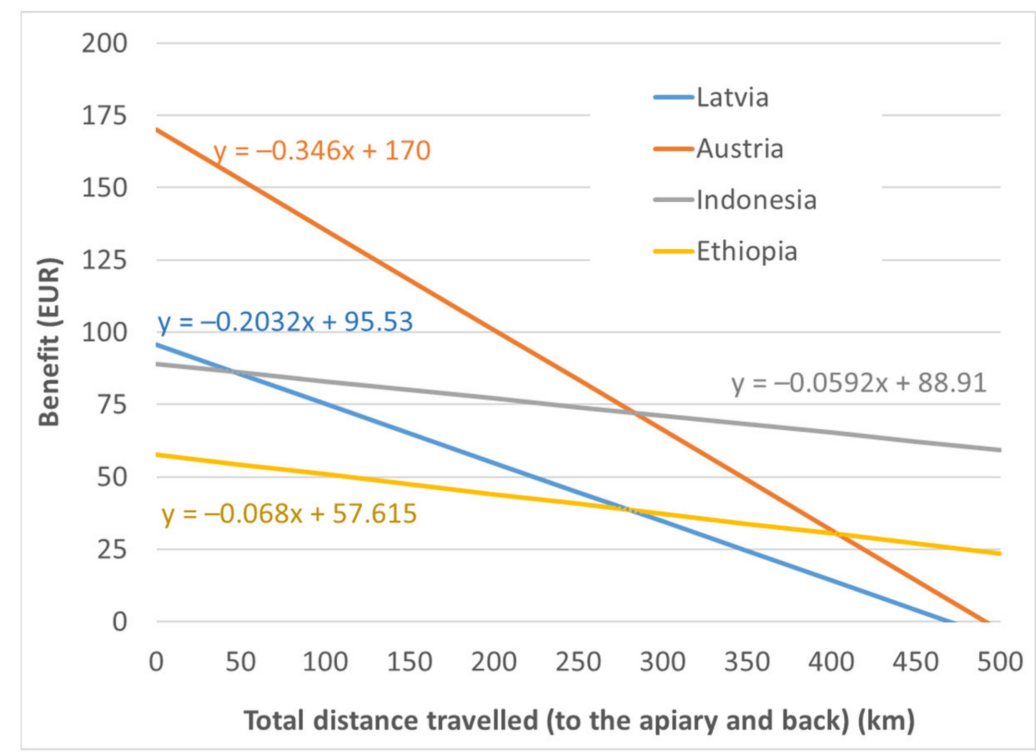

Figure 2. Model outcome showing the relationship between travelled distance and benefit in four different countries.

Figure 3 shows the percentage of benefit in relation to potential losses depending on the distance. Comparing the percentage of benefit in relation to potential losses, Indonesia and Ethiopia are ahead, but the lowest percentage is for European countries (Latvia and Austria). It can be concluded that increasing the distance to the apiary situation in European countries is very similar. Lines do not start at the point of $100 \%$, as catching the swarm needs time and labour costs anyway, even if the distance is $0 \mathrm{~km}$.

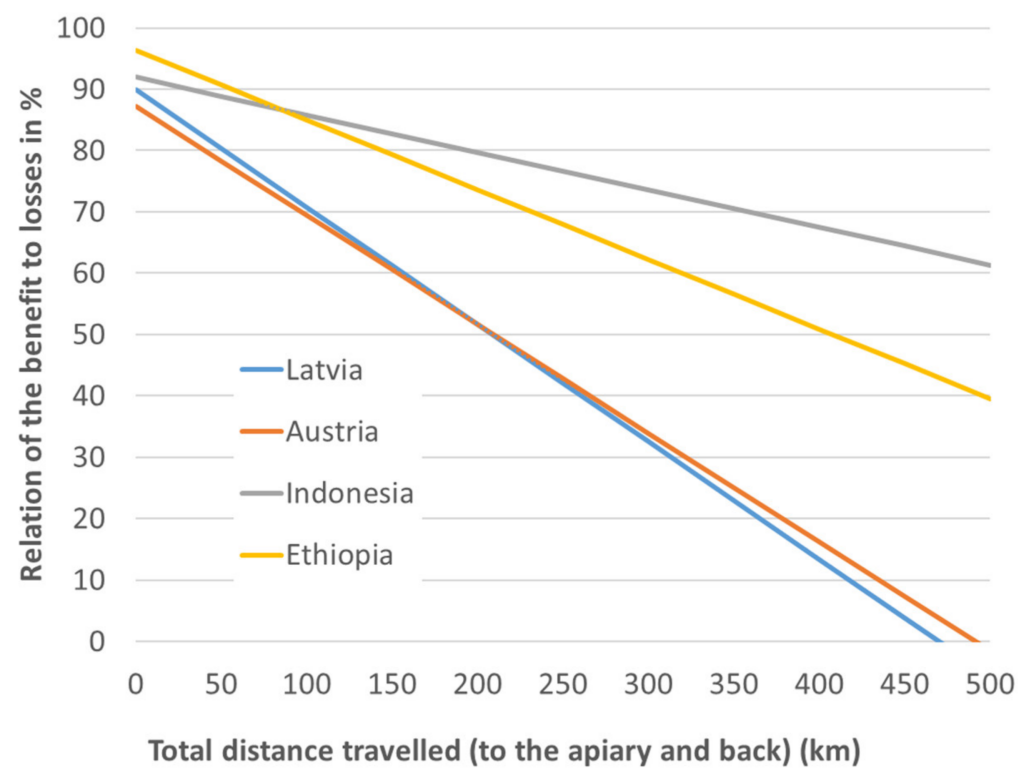

Figure 3. Percentage of benefit in relation to potential losses in dependence on distance.

\subsection{Advanced Economic Model including Swarm Catch Probability}

We developed this model that considers the swarm catching probability, which follows normal distribution, with mean $(\mathrm{mu})=300 \mathrm{~km}$, and standard deviation (fi) $=50 \mathrm{~km}$. These numbers are derived from the assumption of the average swarming period-the time between the event of a swarm leaving the hive to a close-by bush or tree, and to the event of the swarm departing to a new home [37]. In this study, we assume that after $3 \mathrm{~h}$ (sometimes swarms can stay longer $[36,37])$, a swarm is usually gone, so, taking the average travelling speed into account, in $3 \mathrm{~h}$ a beekeeper can go as far as $150 \mathrm{~km}$ one way. As the model 
operates with round-trip costs, we assume that the average travelling distance until the swarm flies away is as far as $300 \mathrm{~km}$. The resulting model is adjusted according to the defined swarm catching probability (Figure 4).

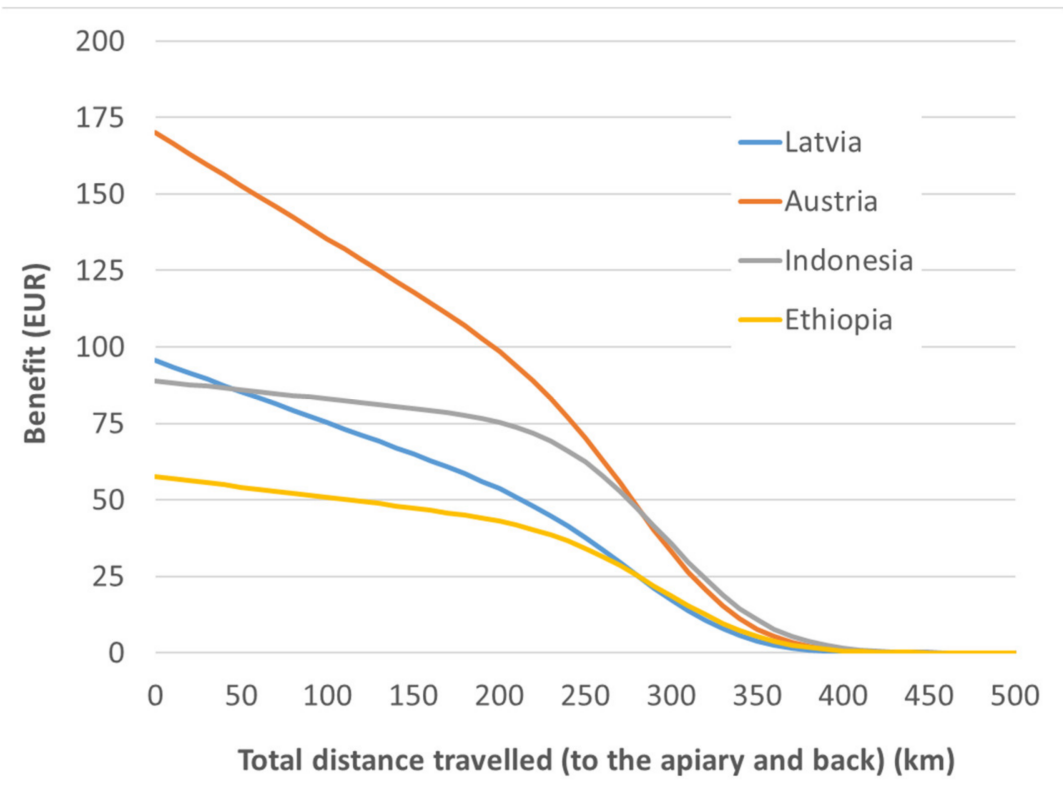

Figure 4. Comparison of the economic benefit of remote swarming detection considering a decrease in swarm catching probability.

Based on the proposed advanced model, the potential distance to the remote apiary, when travelling and catching the swarm will have economic benefit, is decreased. The potential benefit drops at around the distance which corresponds to the average time a swarm stays near the mother colony. The most significant decrease in benefit can again be seen in Austria. More importantly, regardless of the daily wage model in Indonesia, the potential benefit drops close to zero when the swarm is most probably gone (opposite to the first economic model, which predicted a considerable benefit even after whole-day and long-distance travelling).

\subsection{Web Application to Ease the Evaluation of the Benefit of Catching the Swarm}

To ease the process of applying our models and to evaluate the economic feasibility of travelling to a remote apiary to catch a swarm, an online web tool (application) was developed and published for public use (https: / / sams.science.itf.llu.lv/swarm-economy, accessed on 15 June 2021). To use the tool, logging in is required using the button located in the right upper corner (a Google account can also be used). The web tool was built as a single page application using Spring Boot 2 framework (forming back-end) and Angular 6 framework with Bootstrap 4 library to create the client side (front-end) of the application. The application allows users to change input field values to adapt to local requirements (needs, peculiarities) and prices. Users can calculate the swarm value by considering the size of the swarm (as well as the price of a queen), or by estimating its approximate costs (from their own experience). The result is calculated simultaneously, as soon as the required fields are filled. A screenshot of the developed web tool is shown in Figure 5. 
If SAMS DWH Dashboard Nodes Devices Reports Calculatoris -

(- Aleksejs Zacepins`

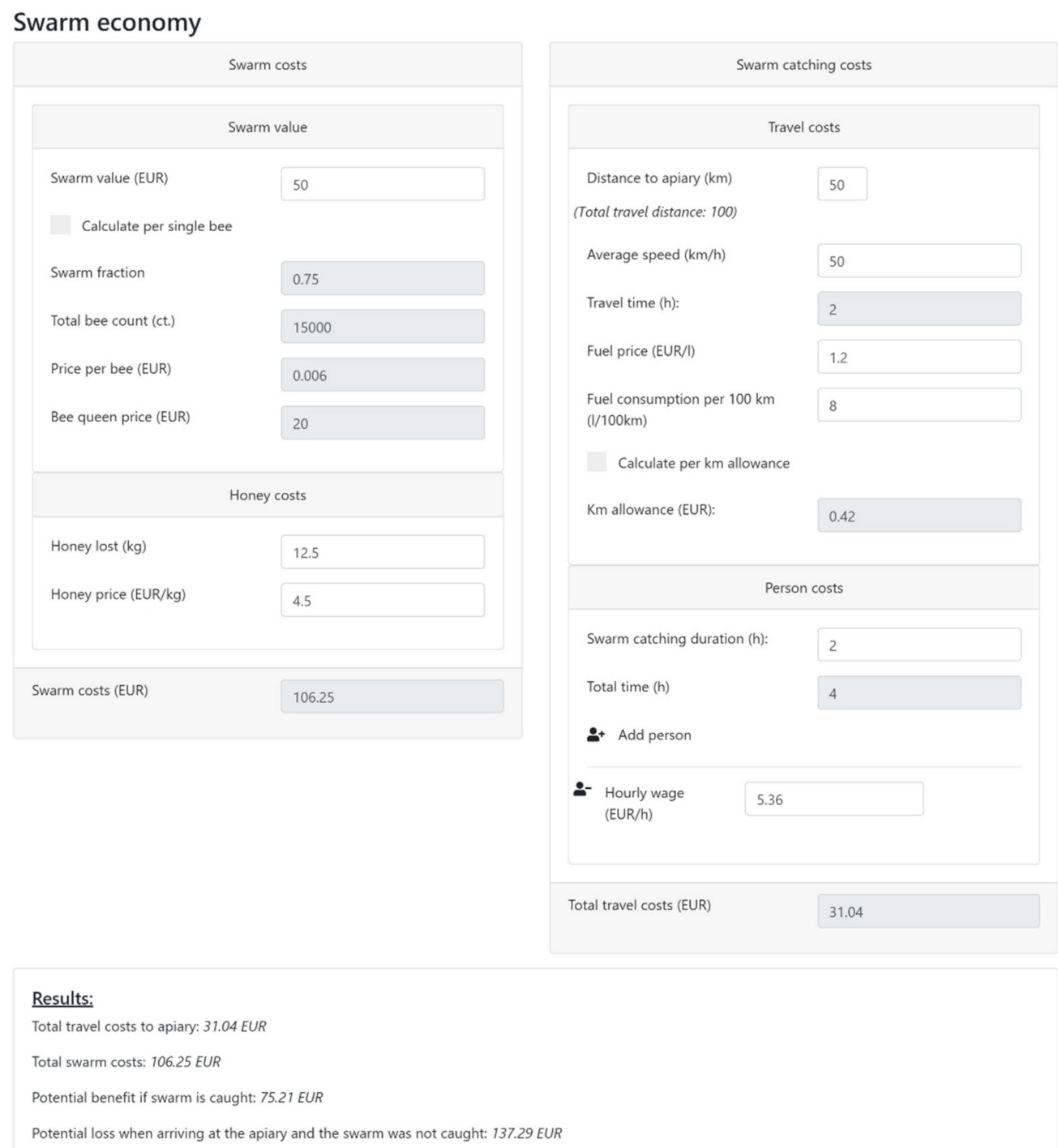

ITF $\$ 2019$

Figure 5. Screenshot of the developed web tool for running the models.

\section{Discussion}

In contrast to the economy of bee products [6], the economics of honey bee management [42], direct economic impact of colony losses [13], indirect economic value of bee pollination [1,4], or effect of bee diseases and colony losses on the apicultural sector $[43,44]$, the economics of some important decisions related to beekeeping are poorly investigated. In this study, we investigate if it pays for a beekeeper to travel to distant apiaries to catch a honey bee swarm. This question arises particularly because remote sensing technology can notify beekeepers about such an event $[17,22,23,30,31,33]$, but our model also supports economic decisions on any other case of swarm capture. While high hopes have been placed in the remote sensing of beehives and precision apiculture, a critical evaluation of the financial benefits is largely missing $[14,38]$.

We, therefore, compared the costs associated with work and travel to catch a honey bee swarm after a remote sensing notification with the potential financial loss of an uncaught swarm. Financial value and percentage of benefit divided by potential loss are both a function of the distance to the apiary. The efforts to collect the swarm are, hence, 
geographically limited because increasing travel and labour costs consume the financial benefits of the caught swarm. Our study includes comparative values from four countries on three different continents, as soon electronic hive monitoring is applied in regions that are not currently using precision beekeeping [15].

A clear benefit of remote bee colony swarming detection can only be confirmed for close-by apiaries. Based on the proposed models, beekeepers can evaluate at what distance to a remote apiary it is economically feasible to travel and catch the swarm, or in more general terms, if it is worth installing a monitoring system. The models can also help migratory beekeepers to better plan the apiary location, as in Indonesia for example, A. mellifera is often put in context with migratory beekeeping [45].

Based on the economic model including travelled distance, the financial benefit of catching a very nearby (zero distance) swarm is highest in Austria and lowest in Ethiopia. Latvia and Indonesia are in between. This is due to different prices for bees and bee products in the countries (Table 1). In the case of zero distance, no travel costs are included. Precision apiculture, of course, allows remote sensing [14], so travelling to remote apiaries must be considered. According to our results, the further away a swarming colony is, the lower the benefit of travelling there to catch the swarm becomes. For instance, in Austria, for each additional $50 \mathrm{~km}$, the benefit decreases by EUR 17.10, in Latvia by EUR 10.16, in Indonesia by EUR 2.96 and in Ethiopia by EUR 3.40. The first economic model suggests that in Ethiopia and Indonesia beekeepers can travel to more distant apiaries than in Latvia or Austria while still gaining financial benefits from catching a swarm. These differences are due to varying travel costs in the four investigated countries, which affects break-even when the benefit of catching a swarm and travel cost is reached. This is lowest for Latvia (470 km travel both ways) and Austria $(497 \mathrm{~km})$, followed by Ethiopia $(840 \mathrm{~km})$ and highest for Indonesia $(1502 \mathrm{~km})$. In our model, we assume that travelling to the remote apiary is done by car, which might not always be possible in all countries. Moreover, travel speed (due to street quality, etc.) will be very different, and realistically, the lower travel speed in Indonesia would drastically reduce the given distance. The different slopes of the function are due to differences in travel and labour costs, and thus are steepest for Austria, followed by Latvia, and lowest in Indonesia.

The model suggests that even travelling more than $200 \mathrm{~km}$ to a remote apiary yields economic benefit for the beekeeper, which does not seem very practical. This model does not consider the success rate of catching a swarm, as the swarm could have found a new nest site by the time the beekeeper reaches the apiary [36,46]. Even if beekeepers arrive at the apiary a few minutes after the swarm leaves the hive, they may not find the swarm. The advanced model presented in Section 3.2, therefore, includes decreasing success rates of catching a swarm as a function of time (distance). It must be noted that there are no empirical data underlying our assumptions about a swarm staying for an average of three hours, and that the departure of the swarm follows a normal distribution function, as assumed by the advanced model. Swarms have even been documented to rest for some days under unfavourable conditions [37]. This is largely influenced by the availability of nesting sites and the weather [40].

Comparing the two developed models indicates that the first economic model predicts far too high travel distances but shows clear differences in the distance before financial break-even among the four different countries. The advanced model including swarm catch probability may better explain the real-world situation, though one could argue that the distances are still very high. In most practical cases, the distance to the apiary will be much less, so the results of calculations for long distances are not so important compared to the short ones. On the other hand, our results depict the high value of a honey bee colony and bee products, especially when contrasted with rather cheap travel and labour costs.

Our study raises some questions that should be clarified in further research to make the use of precision beekeeping instruments more economically beneficial. For example, research on the consequences of false alarms (notification of an event that did not happen) or missed events (no notification despite the event) is required. Research on how long 
honey bee swarms stay near the hive, or how far they initially fly for their first settlement would aid our understanding. We also want to point out some synergistic effects, for example, when other hive management tasks can be accomplished during the travel to catch a swarm.

Eventually, there are growing technical solutions to forecast swarming before swarms take off $[22,23,30,32,33]$. In this case, our first (including travelled distance) economic model should be applied to determine distances for which remote swarm detection is economically feasible. Finally, the price of system implementation in the apiary for individual bee colony remote monitoring should also be considered. This case was not included in this study but should be considered in future investigations. An evaluation of the overall return on investment coefficient of such a system is also necessary. For example, if system installation and maintenance costs are EUR 1000 with a swarming detection benefit of EUR 100 , the system will only pay off after 10 successful detections (of the monitored colony). On the other hand, a remote monitoring system will also have additional benefits, like monitoring the nectar flow or brood rearing state $[14,15]$, decreasing the rate for the return on investments.

\section{Conclusions}

We demonstrated that precision beekeeping and remote sensing (specifically remote bee colony swarming event detection) could be economically beneficial. However, due to several constraints, there are economic and geographic limits for remote sensing. We also demonstrated that these limits greatly depend on economic differences; as such, the suitability of the application of remote sensing systems should be evaluated critically for each field installation. Remote precision beekeeping systems only yield financial benefits in a certain geographic range. Although it is technically possible to transmit data very far, the limit for practical beekeeping is physical attendance at apiaries. The possible technical range is tempting, but we need to stress that remote sensing is limited by the ability to physically reach the apiary and interact in time, or alternatively inform a person living close-by. If this is not possible, or linked to time and resource consuming travel, remote sensing is not feasible. Our economic models quantify this geographic range for honey bee swarming detection for four different countries, but allows extension to any other country or situation via a developed web application. Further web tools for the evaluation of economic benefits of all aspects of remote hive monitoring systems could inform beekeepers of the feasibility of their beekeeping.

Author Contributions: Conceptualisation, A.Z. and R.B.; methodology, A.Z.; software, A.K.; validation, V.K., writing — original draft preparation, A.Z.; writing—review and editing, all authors. All authors have read and agreed to the published version of the manuscript.

Funding: This project received funding from the Horizon 2020 European Union Research and Innovation Framework under Grant Agreement No. 780755-SAMS ("Smart Apiculture Management Services"). The authors acknowledge the financial support for open access by the University of Graz.

Institutional Review Board Statement: Not applicable.

Informed Consent Statement: Not applicable.

Data Availability Statement: Data is contained within the article.

Acknowledgments: The authors thank Fajar Susilo from Universitas Padjadjaran (Indonesia) and Kibebew Wakjira from Oromia Agriculture Research Institute Holeta Bee Research Center (Ethiopia) for providing data for Indonesia and Ethiopia. Open Access Funding by the University of Graz.

Conflicts of Interest: The authors declare no conflict of interest. 


\section{References}

1. Southwick, E.E.; Southwick, J.L. Estimating the Economic Value of Honey Bees (Hymenoptera: Apidae) as Agricultural Pollinators in the United States. J. Econ. Entomol. 1992, 85, 621-633. [CrossRef]

2. Aizen, M.A.; Harder, L.D. The Global Stock of Domesticated Honey Bees Is Growing Slower Than Agricultural Demand for Pollination. Curr. Biol. 2009, 19, 915-918. [CrossRef] [PubMed]

3. Klein, A.M.; Vaissiere, B.E.; Cane, J.H.; Steffan-Dewenter, I.; Cunningham, S.A.; Kremen, C.; Tscharntke, T. Importance of pollinators in changing landscapes for world crops. Proc. R. Soc. B Biol. Sci. 2007, 274, 303-313. [CrossRef]

4. Gallai, N.; Salles, J.M.; Settele, J.; Vaissière, B.E. Economic valuation of the vulnerability of world agriculture confronted with pollinator decline. Ecol. Econ. 2009, 68, 810-821. [CrossRef]

5. Bommarco, R.; Kleijn, D.; Potts, S.G. Ecological intensification: Harnessing ecosystem services for food security. Trends Ecol. Evol. 2013, 28, 230-238. [CrossRef] [PubMed]

6. García, N.L. The Current Situation on the International Honey Market. Bee World 2018, 95, 89-94. [CrossRef]

7. Potts, S.G.; Roberts, S.P.; Dean, R.; Marris, G.; Brown, M.A.; Jones, R.; Neumann, P.; Settele, J. Declines of managed honey bees and beekeepers in Europe. J. Apic. Res. 2010, 49, 15-22. [CrossRef]

8. Van Engelsdorp, D.; Meixner, M.D. A historical review of managed honey bee populations in Europe and the United States and the factors that may affect them. J. Invertebr. Pathol. 2010, 103, S80-S95. [CrossRef]

9. Moritz, R.F.A.; Erler, S. Lost colonies found in a data mine: Global honey trade but not pests or pesticides as a major cause of regional honeybee colony declines. Agric. Ecosyst. Environ. 2016, 216, 44-50. [CrossRef]

10. Brodschneider, R.; Brus, J.; Danihlík, J. Comparison of apiculture and winter mortality of honey bee colonies (Apis mellifera) in Austria and Czechia. Agric. Ecosyst. Environ. 2019, 274, 24-32. [CrossRef]

11. Gray, A.; Brodschneider, R.; Adjlane, N.; Ballis, A.; Brusbardis, V.; Charriere, J.D.; Chlebo, R.F.; Coffey, M.; Cornelissen, B.; Amaro da Costa, C.; et al. Loss rates of honey bee colonies during winter 2017/18 in 36 countries participating in the COLOSS survey, including effects of forage sources. J. Apic. Res. 2019, 58, 479-485. [CrossRef]

12. Gray, A.; Adjlane, N.; Arab, A.; Ballis, A.; Brusbardis, V.; Charrière, J.D.; Chlebo, R.; Coffey, M.F.; Cornelissen, B.; da Amaro Costa, C.; et al. Honey bee colony winter loss rates for 35 countries participating in the COLOSS survey for winter 2018-2019, and the effects of a new queen on the risk of colony winter loss. J. Apic. Res. 2020, 59, 744-751. [CrossRef]

13. Popovska Stojanov, D.; Dimitrov, L.; Danihlík, J.; Uzunov, A.; Golubovski, M.; Andonov, S.; Brodschneider, R. Direct Economic Impact Assessment of Winter Honeybee Colony Losses in Three European Countries. Agriculture 2021, 11, 398. [CrossRef]

14. Zacepins, A.; Brusbardis, V.; Meitalovs, J.; Stalidzans, E. Challenges in the development of Precision Beekeeping. Biosyst. Eng. 2015, 130, 60-71. [CrossRef]

15. Wakjira, K.; Negera, T.; Zacepins, A.; Kviesis, A.; Komasilovs, V.; Fiedler, S.; Kirchner, S.; Hensel, O.; Purnomo, D.; Nawawi, M.; et al. Smart apiculture management services for developing countries-the case of SAMS project in Ethiopia and Indonesia. PeerJ Comput. Sci. 2021, 7, e484. [CrossRef]

16. Meikle, W.G.; Holst, N. Application of continuous monitoring of honeybee colonies. Apidologie 2015, 46, 10-22. [CrossRef]

17. Zacepins, A.; Kviesis, A.; Stalidzans, E.; Liepniece, M.; Meitalovs, J. Remote detection of the swarming of honey bee colonies by single-point temperature monitoring. Biosyst. Eng. 2016, 148, 76-80. [CrossRef]

18. Meikle, W.G.; Weiss, M.; Maes, P.W.; Fitz, W.; Snyder, L.A.; Sheehan, T.; Mott, B.M.; Anderson, K.E. Internal hive temperature as a means of monitoring honey bee colony health in a migratory beekeeping operation before and during winter. Apidologie 2017, 48, 666-680. [CrossRef]

19. Fitzgerald, D.W.; Murphy, F.E.; Wright, W.M.; Whelan, P.M.; Popovici, E.M. Design and development of a smart weighing scale for beehive monitoring. In Proceedings of the 26th Irish Signals and Systems Conference (ISSC), Carlow, Ireland, 24-25 June 2015; pp. 1-6. [CrossRef]

20. Lecocq, A.; Kryger, P.; Vejsnaes, F.; Bruun Jensen, A. Weight watching and the effect of landscape on honeybee colony productivity: Investigating the value of colony weight monitoring for the beekeeping industry. PLoS ONE 2015, 10, e0132473. [CrossRef]

21. Ruan, Z.Y.; Wang, C.H.; Lin, H.J.; Huang, C.P.; Chen, Y.H.; Yang, E.C.; Tseng, C.L.; Jiang, J.A. An Internet of Things-Based Weight Monitoring System for Honey. Int. J. Agric. Biosyst. Eng. 2017, 11, 478-482.

22. Ferrari, S.; Silva, M.; Guarino, M.; Berckmans, D. Monitoring of swarming sounds in bee hives for early detection of the swarming period. Comput. Electron. Agric. 2008, 64, 72-77. [CrossRef]

23. Bencsik, M.; Bencsik, J.; Baxter, M.; Lucian, A.; Romieu, J.; Millet, M. Identification of the honey bee swarming process by analysing the time course of hive vibrations. Comput. Electron. Agric. 2011, 76, 44-50. [CrossRef]

24. Michener, C.D. The Social Behavior of the Bees; Harvard University Press: Cambridge, UK, 1974.

25. Heinrich, B.Y.B. The mechanisms and energetics of honeybee swarm temperature regulation. J. Exp. Biol. 1981, 91, 25-55. [CrossRef]

26. Seeley, T.D. How Honeybees Find a Home. Sci. Am. 1982, 247, 158-168. [CrossRef]

27. Winston, M.L. The Biology of the Honey Bee; Harvard University Press: Cambridge, UK, 1982. [CrossRef]

28. Simpson, J. The incidence of swarming among colonies of honey-bees in England. J. Agric. Sci. 1957, 49, 387-393. [CrossRef]

29. Simpson, J. The factors which cause colonies of Apis mellifera to swarm. Insectes Sociaux 1958, 5, 77-95. [CrossRef] 
30. Kridi, D.S.; de Carvalho, C.G.N.; Gomes, D.G. A predictive algorithm for mitigate swarming bees through proactive monitoring via wireless sensor networks. In Proceedings of the 11th ACM Symposium on Performance Evaluation of Wireless Ad Hoc, Sensor, \& Ubiquitous Networks, Montreal, QC, Canada, 21-26 September 2014; pp. 41-47.

31. Kviesis, A.; Zacepins, A. Application of neural networks for honey bee colony state identification. In Proceedings of the 17th International Carpathian Control Conference (ICCC), High Tatras, Slovakia, 29 May-1 June 2016; pp. $413-417$.

32. Buchmann, S.; Thoenes, S. The electronic scale honey bee colony as a management and research tool. Bee Sci. 1990, 1, 40-47. Available online: http:/ / www.cabdirect.org/abstracts/19910229804.html (accessed on 4 December 2014).

33. Meikle, W.; Hoist, N.; Mercadier, G. Using balances linked to dataloggers to monitor honey bee colonies. J. Apic. Res. 2006, 45, 39-41. Available online: http:/ / cat.inist.fr / ?aModele=afficheN\&cpsidt=17873767 (accessed on 4 December 2014). [CrossRef]

34. Rickli, M.; Bühlmann, G.; Gerig, L.; Herren, H.; Schürch, H.J.; Zeier, W.; Imdorf, A. Zur Anwendung eines elektronischen Bienenzählgerätes am Flugloch eines Bienenvolkes. Apidologie 1989, 20, 305-315. [CrossRef]

35. Campbell, J.; Mummert, L.; Sukthankar, R. Video monitoring of honey bee colonies at the hive entrance. Vis. Obs. Anal. Anim. Insect Behav. 2008, 8, 1-4.

36. Villa, J.D. Swarming behavior of honey bees (Hymenoptera: Apidae) in southeastern Louisiana. Ann. Entomol. Soc. Am. 2004, 97, 111-116. [CrossRef]

37. Seeley, T.D. Honeybee Democracy; Princeton University Press: Princeton, NJ, USA, 2010.

38. Zacepins, A.; Stalidzans, E.; Karasha, T. Profitability ranking of precision agriculture measurement systems implementation. In Proceedings of the 12th International Scientific Conference “Engineering for Rural Development, Jelgava, Latvia, 23-24 May 2013; pp. 164-169.

39. Caron, D.M.; Connor, L.J. Honey Bee Biology and Beekeeping; Wicwas Press: Kalamazoo, MI, USA, 2013.

40. Seeley, J.; Rangel, T.D. Colony fissioning in honey bees: Size and significance of the swarm fraction. Insectes Sociaux 2012, 59, 453-462. [CrossRef]

41. BMNT. Grüner Bericht (2018) Bericht Über die Situation der Österreichischen Land- und Forst-Wirtschaft im Jahr 2017. Available online: https:/ / gruenerbericht.at/cm4/jdownload/send/2-gr-bericht-terreich/1650-gb2016 (accessed on 15 May 2021).

42. DeGrandi-Hoffman, G.; Graham, H.; Ahumada, F.; Smart, M.; Ziolkowski, N. The Economics of Honey Bee (Hymenoptera: Apidae) Management and Overwintering Strategies for Colonies Used to Pollinate Almonds. J. Econ. Entomol. 2019, 112, 2524-2533. [CrossRef] [PubMed]

43. Rucker, R.R.; Thurman, W.N. Colony Collapse Disorder: The Market Response to Bee Disease; PERC policy series; PERC: Bozeman, MT, USA, 2012; p. 32.

44. Thurman, W.; Rucker, R.; Burgett, M. Colony Collapse and the Consequences of Bee Disease: Market Adaptation to Environmental Change. J. Assoc. Environ. Resour. Econ. 2019, 53, 704360. [CrossRef]

45. Gratzer, K.; Susilo, F.; Purnomo, D.; Fiedler, S.; Brodschneider, R. Challenges for Beekeeping in Indonesia with Autochthonous and Introduced Bees. Bee World 2019, 96, 40-44. [CrossRef]

46. Kohl, P.L.; Rutschmann, B. The neglected bee trees: European beech forests as a home for feral honey bee colonies. PeerJ 2018, 6, e4602. [CrossRef] [PubMed] 